\title{
Uganda's HIV/AIDS Epidemic: Guest Editorial
}

\author{
Michael Merson
}

Published online: 11 July 2006

(C) Springer Science+Business Media, Inc. 2006

Uganda has been of great interest to those following the HIV/AIDS pandemic because it is the only country that has successfully reversed a generalized, high prevalence epidemic. HIV prevalence in the country decreased from as high as 30\% in 1992 among women attending some urban antenatal clinics to as low as $6 \%$ in 2000 among pregnant women throughout the country. Although there are a few other "success" stories in the history of the pandemic, such as the significant decrease in HIV prevalence and incidence observed among gay men in the United States in the late 1980s and early 1990s, Uganda remains unique among nations.

It is thus not surprising that much effort has been made to determine the cause of the decline in HIV prevalence in Uganda. While it is tempting to try and identify a single reason, public health experience with control of sexually transmitted diseases would suggest that there would be multiple contributing factors to this decline. Indeed, as Gray, Serwadda, Kigozi, Nalugoda, and Wawer (2006, this issue) point out, it may never be possible to fully disaggregate the contributions to the decrease in HIV prevalence. These include a decline in HIV incidence as a result of behavior change, social cultural influences such as postwar social stabilization, and the natural evolution of the epidemic, particularly high mortality rates and less transmission by those with early, acute infection. Other factors that also likely contributed to the decline in HIV prevalence were: strong leadership by the head of state (Uganda was the first country to have a multi-sectoral AIDS Commission under the auspices

M. Merson $(\square)$

Center for Interdisciplinary Research on AIDS,

Yale University School of Medicine,

New Haven, Connecticut of the President), an active civil society response and an early emphasis on voluntary counseling and testing.

There has been much controversy around the relative importance of various components of behavior changeabstinence, partner reduction, condom promotion-in contributing to the decline in HIV prevalence. As Slutkin et al. (2006, this issue) point out, all these options for behavior change were promoted in the unique and large health education campaign that took place in the country during the period immediately prior to the decline in HIV prevalence. The actual "ABC" phrase was never used and the word "abstinence" per se was rarely heard or written anywhere. Retrospectively, as Green, Halperin, Nantulya, and Hogle (2006, this issue) conclude, it appears that the greatest change in behavior was in reduction of partners, but this in and of itself cannot account for the drop in prevalence that was observed. Increased use of condoms was also an important contributor in Uganda's HIV prevention programs.

As Slutkin et al. ( 2006) emphasize, the observed behavior change should not be attributed to one behavior change component or another, but rather to the intensity and breadth of the health education campaign, as illustrated by its deep extension into communities and strong financial support. The prevention success of Uganda is thus attributable to the provision of full information about all means of transmission and protection by many sectors of society, along with efforts to destigmatize HIV/AIDS by being open about the disease, showing compassion and providing care to those who are infected and affected. Those who are skeptical about the potential effectiveness of behavior change programs need to realize what the Uganda experience tells us, namely that these programs can only be successful if they are comprehensive, well funded, and given the priority that today is being awarded to treatment with antiretroviral drugs. 
This brings us to the current situation in Uganda. There is recent evidence which indicates that HIV prevalence is no longer on the decline and, in fact, may be increasing in some parts of the country and particularly in adults aged in their 30s (Wakabi, 2006). One possible cause for this may be behavioral disinihibition, resulting from the substantial and successful roll out of antiretroviral therapy in the country. Another may be the unfortunate rhetoric surrounding the relative importance of the $\mathrm{A}, \mathrm{B}$ and $\mathrm{C}$ components that now exists throughout the country and the subsequent great confusion regarding the promotion and effectiveness of condoms. The fact that as much as $60 \%$ of all new HIV infections are today occurring in HIV serodiscordant couples alone illustrates the folly of relying on a predominantly abstinence-based strategy as a basis for prevention. To avoid a resurgence of HIV infection in Uganda, prevention strategies should be based on local epidemiological information about HIV transmission patterns and not on arbitrary donor policies regarding the relative importance and funding levels of the various $\mathrm{ABC}$ component activities. Better yet, why not remove the $\mathrm{ABC}$ slogan from our prevention vocabulary, and instead work to be sure that prevention programs are comprehensive and not judgmental. Today's prevention efforts also need to be linked to new efforts in AIDS treatment. This means that all clinics and field staff providing antiretroviral drugs should be sure to provide full information about HIV prevention to all patients along with an ample supply of free condoms. The consequences of doing otherwise are obvious.

\section{References}

Green, E.C., Halperin, D.T., Nantulya, V., \& Hogle, J. (2006). Uganda's HIV prevention success: The role of sexual behavior change and the national response. AIDS and Behavior.

Gray, R.H., Serwadda, S., Kigozi, G., Nalugoda, F., \& Wawer, M.J. (2006). Uganda's HIV prevention success: The role of sexual behavior change and the national response. Commentary on Green et al. (2006). AIDS and Behavior.

Slutkin, G., Okware, S., Namaara, W., Sutherland, D., Flanagan, D., Carael, M., Blas, E., Delay, P., \& Tarantola, D. (2006). How Uganda reversed it's HIV epidemic. AIDS and Behavior.

Wakabi, W. (2006). Condoms still contentious in Uganda's struggle over AIDS. Lancet, 367, 1387-1388. 